\title{
Identification and evaluation of criteria for selecting contractors using a risk management approach
}

DOI 10.2478/otmcj-2018-0004

Received October 18, 2017; accepted April 01, 2018

\begin{abstract}
Transferring all or some parts of the engineering activities or supply of goods to third persons or companies is one of the adopted methods that transfer a significant part of the likely risks to the concerned side. Outsourcing activities are followed by many benefits, such as reducing overhead and operational costs, increasing efficiency, reducing risk, and so on; however, if this is not done carefully, not only is no benefit gained, but also new risks are imposed on the organization. Considering that waste of time and cost diversions of projects stem from the selection of inappropriate contractors, risk assessment is important in outsourcing.
\end{abstract}

Using a risk-oriented approach based on software toward outsourcing, the present study aims to identify and rate the factors affecting the selection of contractors and to finally provide a method to evaluate and select the proper way for the selection of contractors. This method is not just based on the lowest price, but it also includes several factors that influence the selection of contractors, which is achieved by applying the Expert Choice software. At first, the most important risk factors in the selection of contractors were identified according to the conducted research. Then, the factors that had the greatest risk potential for achieving the project goals were chosen from among them. The opinions of experts were obtained in the next phase to determine the importance of various factors in the process of contractor selection, which was achieved by the distribution of a questionnaire. Subsequently, the most important factors chosen by the experts were specified, and their relationship with the contractor's risk management was found.

*Corresponding author: Ehsan Mousakhani, McWhorter School of Building Science, Auburn University, AL, USA, E-mail: emosakhani@aut.ac.ir

Shirzad Ranjbar, Department of Civil Engineering, Amirkabir University of Technology, Tehran, Iran,

Taha Ashoori, Department of Civil Engineering, University of Texas at Arlington, TX, USA
Keywords: contractor, risk, tender, outsourcing, contract, analytic hierarchy process (AHP)

\section{Introduction}

\section{Statement of the problem}

Contractors play a major role in accomplishing construction projects; therefore, the selection of contractors is an important decision for a client. The complexity and difficulty of the construction industry have intensified different risks and uncertainties that affect the ultimate performance level of the contractors. On the failure of contractors, clients will not be successful in achieving the ultimate goals of the project in terms of cost, time, and quality (Haghighi Fard, 2010). Because inappropriate selection of contractors affects the main project's goal negatively, providing a process that can solve such problems is crucial for the clients. To tackle the problem, clients also require a filter to prevent the entry of unqualified contractors into the tendering process (Rajae and Hazrati, 2007).

Research has shown that determining a contractor just based on the proposed price (traditional approach to contractor selection) does not entail long-term interests for the client, and selecting the most qualified contractor requires the use of a comprehensive set of criteria and indices. This set of indices can evaluate and estimate the competence level of the contractor to implement the project in terms of the most important items, namely, cost, time, and quality (Mohagher et al., 2012).

\section{Risk management in the bidding phase}

The introduction of risk management in the bidding process increases the opportunities of success in future projects (Edmundo and Ingrid, 2012). In a construction contract, a client generally allocates his risks to the chosen 
contractor. The inability of the contractor to adequately manage the risks still will has consequences for the client, especially in relation to delays in and impact on the thirdparty property. At the tendering stage of a construction contract, the technical contents and the risks associated with the work are less defined than under conventional contracts. Thus, it is important that considerable effort is made during project conception to identify the sources of all risks. During the tendering process, a method must be adopted whereby the individual bids can be assessed for their total risk content to the client, and the result of these quantified assessments must be used in the selection of the economically most advantageous contractor.

Risk management in the bidding process has not yet been performed in a systematic and proper manner, which has led to decision-making with a high risk level, based on expert judgment, assumptions, and intuitive sense, increasing the probability of making wrong decisions.

\section{Literature review}

The selection of an appropriate contractor definitely has a significant impact on the performance of the entire project process, and it is also considered the most important responsibility of the client. Sari and El-Sayegh (2007) describe contractor selection as a complicated procedure. Contractor selection is also explained as an indispensable condition for the proper processing and completion of a construction project (Huang, 2011). Choosing a good contractor enables better realization of the project's goals and objectives (Plenkiewicz, 2009). According to Alhazmi and McCaffer (2000), selection of a proper construction contractor increases the chances of successful completion of the project (Alhazmi and McCaffer, 2000).

Risk factors pertaining to the phase of bidding from the contractors' viewpoint have been identified, while rarely have they been discussed from the clients' viewpoint. For instance, Samuel and Will (2011) stated that three tiers of risk apportionment in bids can be identified.

Tier 1: intuitive risk allowances included in the tender program and price by estimators and planners to compensate for inaccuracies and errors in estimates;

Tier 2: bid teams tend to include an allowance in the bid for the identified risks in a project; and

Tier 3: a firm's management decides on the appropriate level of residual risk allowance to include in a bid.

Thus, different individuals and teams influence pricing levels at different stages of the bid calculation process. Sometimes, price risks may be excluded from a bid to enhance the chances of winning a job. The tender adjustments for risk may take considerable time to decide, but the actual arithmetic involved in reducing or increasing the final price tends to be simpler than the sophisticated prescription of analytical models. Thus, analytical models may be too time consuming, too complex, and insensitive to the commercial exigencies of bidding practice. The findings explain why some assumptions underpinning analytical models may not be sustainable in practice and why what actually happens in practice is important for those who seek to model the pricing of construction bids. Jaselskis, and Russell (1992) conducted an evaluation using a decision tree. Comparison of project costs for good, moderate, and weak clusters shows that more effort is made to evaluate contractors in projects with high costs. Accordingly, less effort is made to evaluate contractors in small projects.

However, previous studies have identified selection of contractors based on cost or bid amount as being one of the contributors to project performance problems. For instance, Gary (2010) suggested that deciding a contractor on the basis of the lowest bid may affect project performance in terms of cost, quality, and time. According to the study, potential performance evaluation of the construction contractors is often neglected when they are chosen based on the strength of their bid amount. Another study indicated that choosing contractors based on wrong criteria may lead to poor performance (Zavadskas et al., 2015). Iyer et al. (2005) suggested poor contractor selection as one of the factors contributing to adverse construction results. They argued that selection of a competent contractor, rather than one with the lowest bid amount, could have a positive influence on the project's cost performance.

Sik et al. (2000) conducted a study analyzing the selection of contractors using the analytic hierarchy process (AHP). According to their investigations, the bid price is usually the most important - or even the only - criterion in selecting a contractor. As the successful accomplishment of a project depends on the ability of contractors to perform appropriately, the lowest price is the main challenging criterion for many authors.

Some theoretical models have been proposed by researchers to make the most optimal decision in the contractor selection process. According to the model of Nieto-Morote and Ruz-Vila (2012), pre-evaluation makes it possible to hold the tender only with qualified contractors. Pre-evaluation is a multi-criteria decision that is largely dependent on the nature of uncertainty and the ambiguity of construction projects, as well as the subjective judgment of the decision-maker. Plebankiewicz (2009) believes that by using the fuzzy method, all evaluations can be 
expressed in the form of a linguistic value. His study aimed to present a model for contractors' pre-evaluation, which included the two steps of use of a "standard list" and "pre-evaluation in any project", and presented a model using the fuzzy theory for pre-evaluation. The results showed that for the client, the degree of importance of the criteria will have the greatest impact on the final results. In addition, software was designed to evaluate the contractors using a standard list and then to select them for a specific project, making it easy for the client.

\section{Summary of the review of previous studies}

First, risk factors pertaining to the phase of bidding from the contractors' viewpoint have been identified, while rarely have they been discussed from the clients' viewpoint. Secondly, as the construction process highly depends on the ability of contractors to perform appropriately, the selection of contractors by just considering the lowest price is the main challenging criterion for many authors. In addition, the degree of importance or weight of criteria is often associated with personal judgment and taste, so the usage of questionnaires can tackle such problems.

However, in some studies, the method proposed to evaluate the factors influencing the selection of contractors has some complications. For example, in one of the papers presented on the subject of weighting contractors' evaluation index (Asgharizadeh and Nasrollahi, 2009), the averaging method (geometric mean) has been used to integrate different questionnaires. The applied method is not appropriate, firstly, because the mean largely integrates positive and negative thoughts and hinders the achievement of actual results. Secondly, there is no need to use the averaging method among numbers announced by experts when the Expert choice software is used, because the software is able to receive different questionnaires and convert them to a unit questionnaire.

Last but not the least, the number of criteria for evaluation did not look right in similar previous studies. In some studies, about 50 criteria are considered to evaluate the contractor. It seems that a large number of criteria not only do not help but also are somewhat misleading and cause the omission of some very important criteria needed to evaluate the contractors. Figure 1 shows an example of criteria useful for evaluation.

As this figure implies, important items such as "contractors' machinery and equipment", "low experience of participation in similar works", "previous connection with the client", and "low credibility of the company" are assigned small weights, which does not explain their real importance at all. Therefore, it is suggested to investigate the previous studies properly and then select the evaluation criteria accordingly in order to avoid such errors.

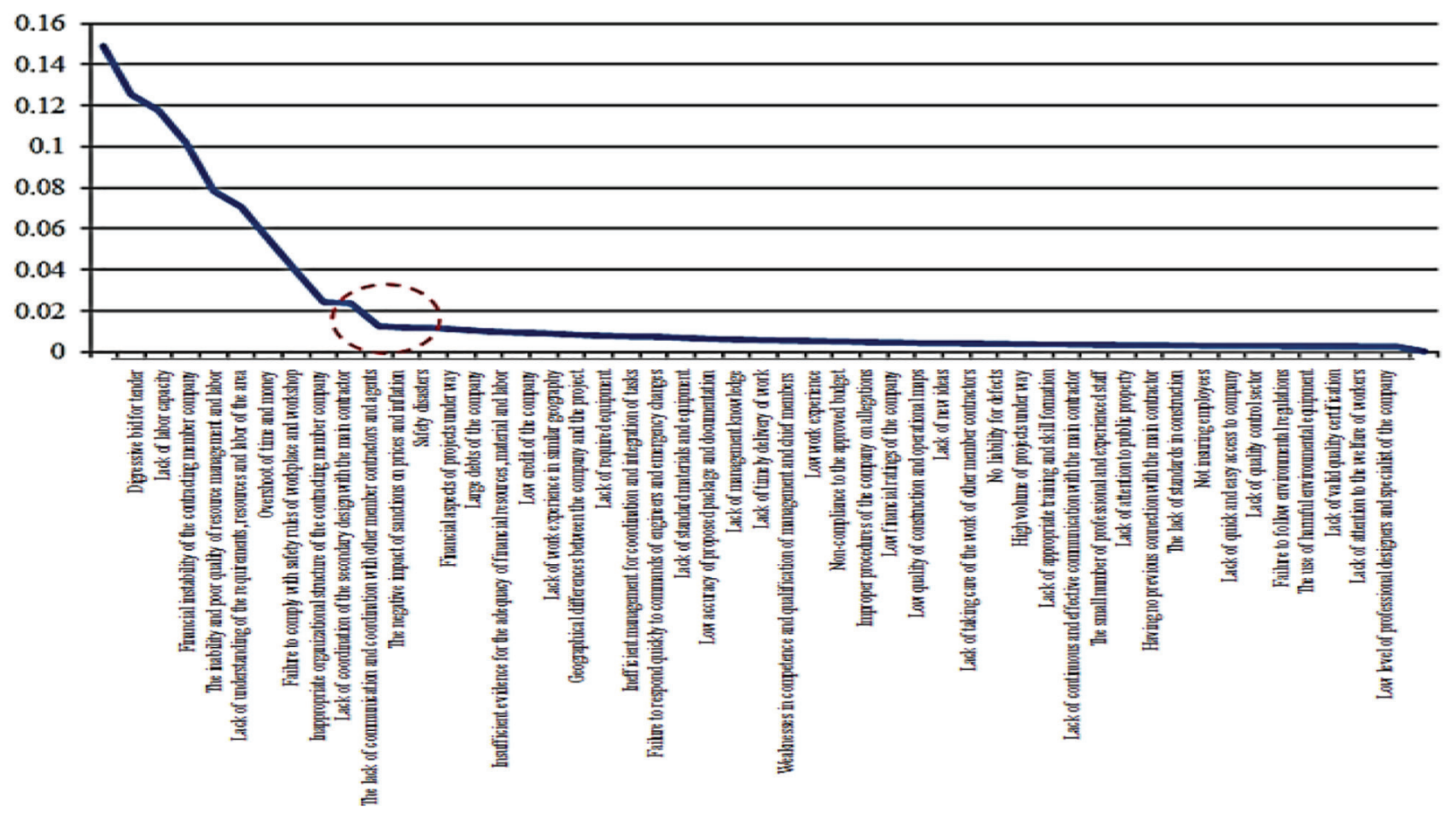

Fig. 1: An example of the criteria considered for contractors' evaluation in previous studies. 
There was a need for a table of criteria distribution in previous studies to select the final criteria that should be considered for the questionnaire. Accordingly, a limited number of criteria with the maximum number of repetitions in previous studies were selected to be included in the questionnaire and the final evaluation.

In most studies, the following criteria have been used as main factors to evaluate or rank the contractor: previous collaboration records, having done the same work, quality, affordability, price of the project, compliance to timing, management knowledge, and so on. Figure 2 shows the different factors used to evaluate contractors in various studies.

\section{Methodology}

In this study, a two-step procedure was adopted for contractor selection. These steps included pre-evaluation and the final selection of the contractor. In the preevaluation step, information such as ratings, financial strength, similar work experience, the quality of previous work, history of establishment of the company, key personnel, and so on is obtained from the contractors, and the contractors are rated accordingly. In the next step, technical and commercial recommendations are requested from the accredited contractors. With respect to the proposed weighted price of each of the contractors, points are awarded to each of the contractors and then the winning contractor is determined with regard to the rates. One of the most important actions in this step is weighting each of the factors upon which the technical-commercial proposal of each of the contractors is to be rated. This is done in several stages. At first, the factors required for the assessment must be determined according to previous studies. After selecting the factors, weights are assigned to the factors and the most important ones are determined using a questionnaire designed based on the AHP and also by obtaining experts' opinion. After distributing the questionnaire and collecting data, the mean of experts' opinion is required. Calculating the mean using manual calculations is very difficult and time consuming and must be done using software. After entering the data into the software and applying the required settings, the software classifies factors into numbers between zero and one, the sum of which equals one. The factor with the larger number is the most important one. Contractor selection according to the chosen factors is the final stage, and before that, the status of each contractor is determined using the chosen factors. After determining the priority of each of the contractors in terms of each of the factors and entering the contractors' data into the software and performing the necessary calculations, the priority of each contractor is extracted. The contractors' priority will also be displayed by numbers from zero to one, the sum of which is equal to one. Naturally, the contractor whose number is larger is the winner of the tender. The selection process is done according to the proposed algorithm shown in Figure 3.

AHP was used for the second phase of contractor selection. In this procedure, the literature was reviewed, and $>20$ articles as well as foreign and domestic dissertations on the topics of risk management, contractor selection, contractor pre-evaluation, and so on were studied to extract the criteria for contractor selection. The study examined $>50$ criteria. Among these criteria, the ones that were most relevant to the risks associated with the workability of the construction process were selected.

After selecting the contractor selection criteria, rating the criteria was next on the agenda. Considering

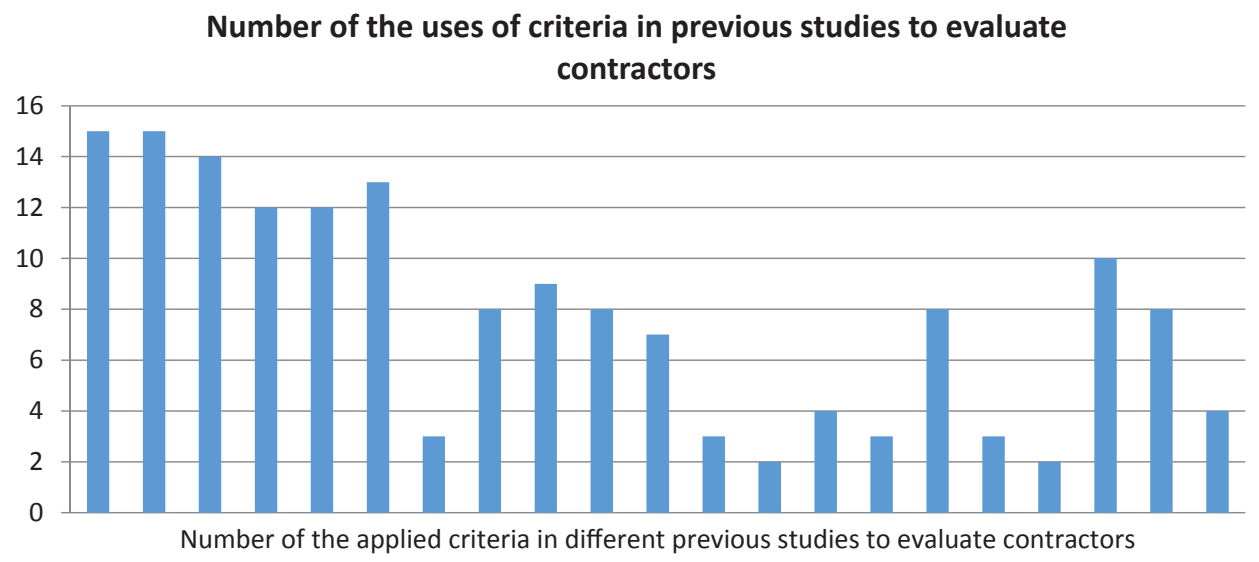

Fig. 2: The number of criteria applied in previous studies to evaluate contractors. 


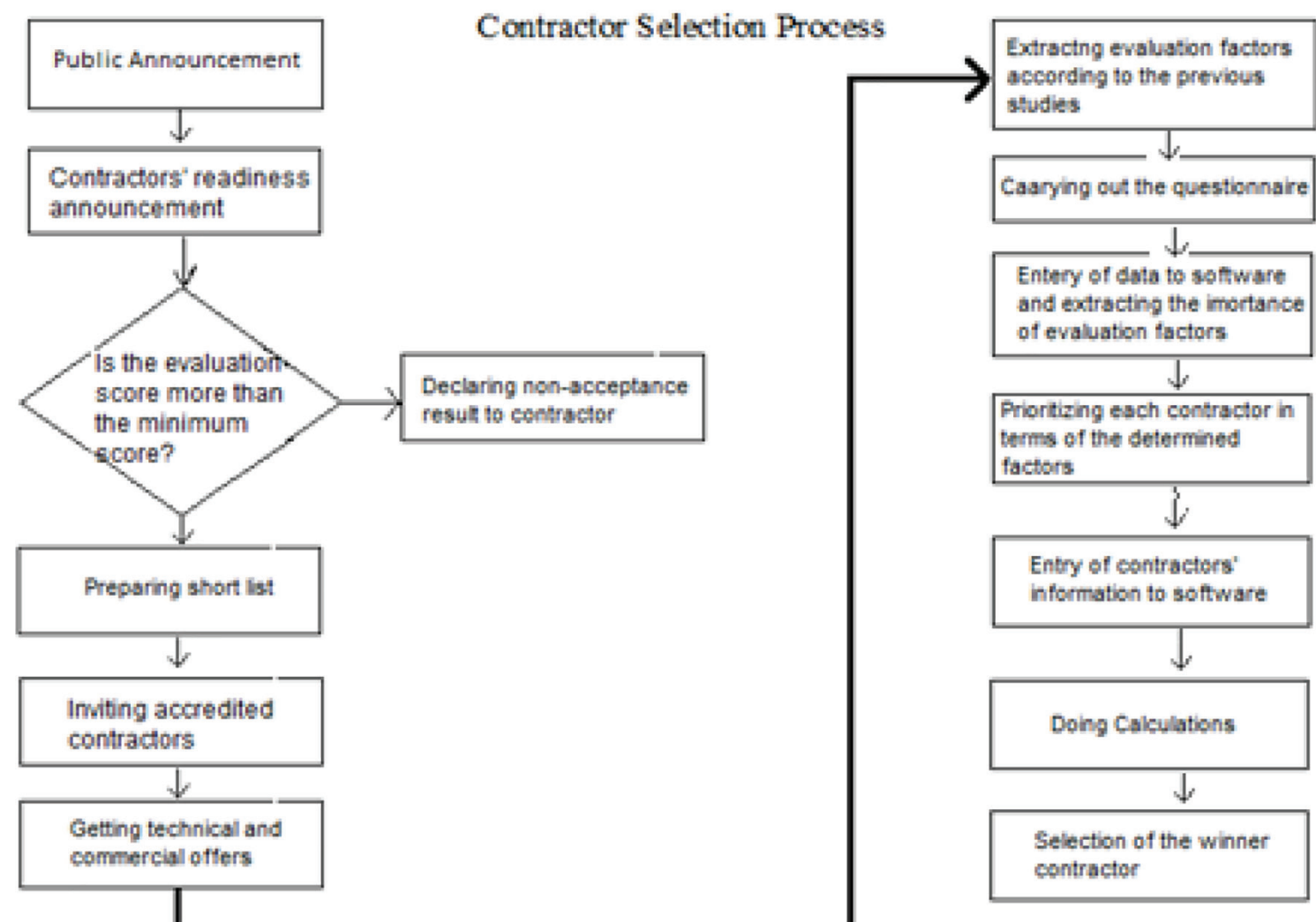

Fig. 3: The algorithm of the contractor selection process.

that the AHP was considered for the selection of contractors, a questionnaire was designed for a pairwise comparison of criteria. The 78-item questionnaire, which could achieve pairwise comparison of parameters, was distributed among senior, middle, and executive managers, as well as to experts of several contracting companies, clients, and advisers. Of the total 45 questionnaires administered, 36 questionnaires were completed and returned.

In the next step, the rating of each of the selected contractors was required for each evaluation criterion. In this regard, a paired comparison matrix was used for each factor. The priority of each of the contractors was determined for the individual evaluation factors.

The information contained in the questionnaires was entered into the Expert Choice software. After entering information on all of the criteria, as well as the information related to the rating of each of the contractors, into the software, analysis was carried out, and the best contractor was chosen as a result of this analysis. The software displays the value of each contractor using a number from zero to one, the sum of which is equal to one. The contractor whose number is larger is the winner of the tender. Therefore, the winning contractor is determined according to the output value of the software.
AHP can be applied to analyze and convert complicated and complex issues to a logical and simple hierarchy. In this study, AHP is adopted because it enables the checking of the compatibility of judgments. On the other hand, the simultaneous use of qualitative and quantitative criteria makes it a powerful tool for issues such as the selection of contractors. In addition, the flexibility, simplicity of calculations, and the possibility of final ranking of options can be effective aids in the investigations (Anagnostopoulos and Vavatsikos, 2006).

Since each construction project is unique, selection of the final contractor through AHP is more flexible than adding or reducing a criterion for clients. Moreover, the strengths and weaknesses of each qualified contractor also become apparent.

\section{Research implementation steps}

At first, the questionnaires were distributed among 45 contractors, consultants, and clients with $>5$ years of work experience who were in the age range between 28 and 45 years. A total of 36 questionnaires were completed and returned. Of these, 30 were reliable questionnaires 
because some of the answers in the remaining six questionnaires were contradictory.

Then, from the completed questionnaires, $>50$ factors useful for contractor evaluation were identified, of which, 13 included the highest risks in the contractor selection process. These factors are shown in Table 1.

The next step was to develop a questionnaire. A questionnaire was prepared based on paired comparisons, and it was distributed among the authorities. After receiving the completed questionnaires, responses were entered into the Expert Choice software. Figure 4 shows an

Tab. 1: The 13 highest-risk factors.

\begin{tabular}{|c|c|}
\hline $\begin{array}{l}\text { Past relationship with } \\
\text { contractor }\end{array}$ & $\begin{array}{l}\text { Financial statements and } \\
\text { contractor's financial stability }\end{array}$ \\
\hline Contractor's bid price & $\begin{array}{l}\text { The work experience in terms of } \\
\text { performance of similar projects }\end{array}$ \\
\hline $\begin{array}{l}\text { Quality of the past } \\
\text { performance of the contractor }\end{array}$ & $\begin{array}{l}\text { Claims and legal issues in the } \\
\text { previous projects of the contractor }\end{array}$ \\
\hline $\begin{array}{l}\text { Appropriateness of contrac- } \\
\text { tor's organization chart }\end{array}$ & $\begin{array}{l}\text { Documented program of risk man- } \\
\text { agement in contractor's company }\end{array}$ \\
\hline $\begin{array}{l}\text { HSE and rate of incident in the } \\
\text { previous projects }\end{array}$ & $\begin{array}{l}\text { Having machinery and equipment } \\
\text { appropriate to the project }\end{array}$ \\
\hline $\begin{array}{l}\text { Accuracy of the documents in } \\
\text { technical proposal }\end{array}$ & $\begin{array}{l}\text { Contractor's past record in terms of } \\
\text { observing timing }\end{array}$ \\
\hline
\end{tabular}

Sufficient knowledge of the site, resources, and labor. HSE - Health, Security and Environment. example of input data into the software and the weights for each criterion calculated by the software.

\section{Questionnaire Number 1}

Figure 4 shows the result from the entry of data from Questionnaire Number 1 into the software. As can be seen, the numbers in the figure indicate the priority of factors when compared to each other. The black numbers indicate the priority of row factors as compared to the column factors, and the red numbers indicate the priority of column factors when compared to the row factors. After entering the data, the software displays the importance of the factors in the form of the following table. According to Questionnaire Number 1 (Figure 5), the past relationship between the client and the contractor has the greatest importance, with the factors "price" and "quality of past performance" following next. "Time performance in the past" was ranked next.

\section{Questionnaire Number 2}

In Questionnaire Number 2, the software assigned the greatest importance to the factor "performance of similar projects"; "past relationship between the client and the

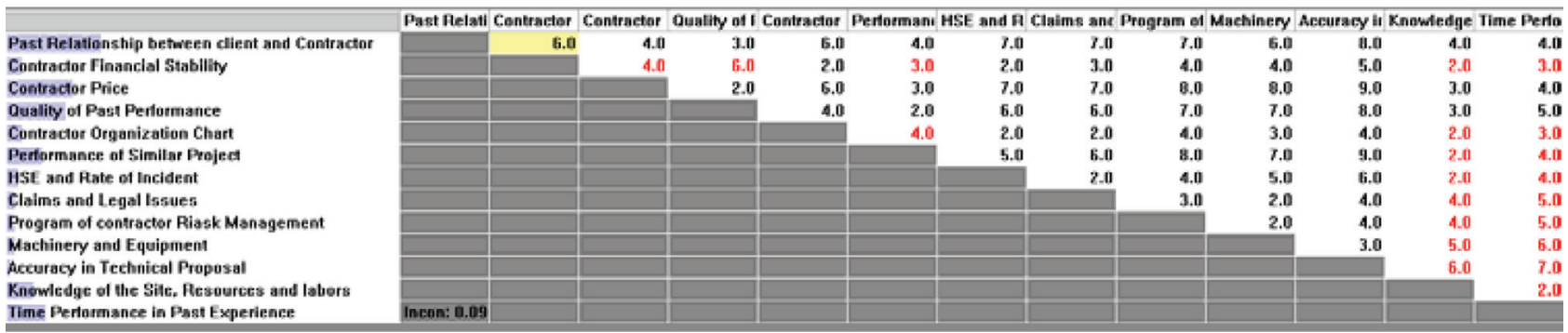

Fig. 4: The result from entry of data from Questionnaire Number 1 into the software.

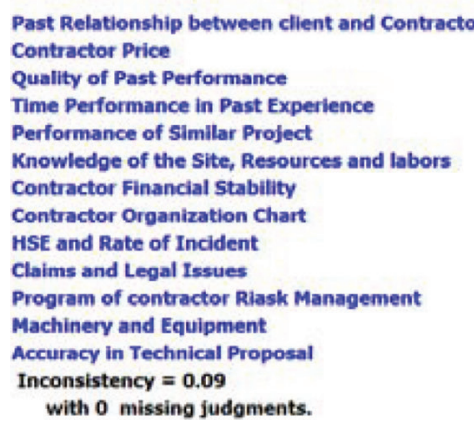

Fig. 5: Displaying the importance of factors.

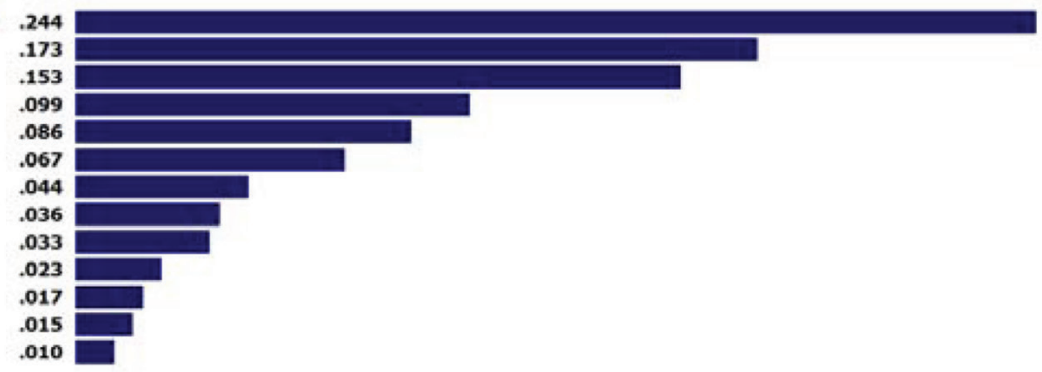


contractor" and "time performance in the past" were ranked next (Figures 6 and 7).

After entering the information of all the questionnaires and combining them, the information of all the questionnaires is included in a single questionnaire as the average (Figure 8).

As Figure 8 shows, all of the information on the contractors has been changed into a unified form, and the weight table thus obtained represents the mean of the questionnaires. According to the final questionnaire, the factor "past relationship" was deemed to have the greatest importance. The factors "contractor's financial stability", “contractor price”, and "time performance in the past" were ranked in the next level of importance. Table 2 summarizes the weights assigned to each factor.

\section{Contractor selection framework with the risk management approach}

Review of the obtained weights shows that five out of the 13 criteria have been assigned around $50 \%$ of the total weights of all criteria. In other words, these five criteria were more important than others in the selection process, and they can change the results in favor of a contractor who has more points in terms of these items.

\begin{tabular}{|c|c|c|c|c|c|c|c|c|c|c|c|c|c|}
\hline & Past Plelatí & Contractor & Contractor & Duality of 1 & Contractor & Pertormant & HSE and R & Claims ans & Program of 1 & Machinery & Accurscy in 1 & Knowledge 1 & Time Perto \\
\hline Past Relatioeship between client and Contractor & & 5.0 & 2.0 & 4.0 & 8.0 & 2.0 & 7.0 & 7.0 & 9.0 & 5.0 & mo & 5.0 & $\mathbf{2 0}$ \\
\hline Contractor Finaecisl Stabiliny & & & 4.0 & 2.0 & 5.0 & 6.0 & 5.0 & 4.0 & 7.0 & 30 & 5.0 & 1.0 & 3.0 \\
\hline Contracter Price & & & & 3.0 & 8.0 & 3.0 & 7.0 & 6.0 & 9.0 & 5.0 & s.o & 4.0 & 4.0 \\
\hline Ouality of Past Pertormanee & & & & & 6.0 & 40 & 5.0 & 40 & 7.0 & 3.0 & 5.0 & 2.0 & 2.0 \\
\hline Contractor Organization Chart & & & & & & 8.0 & 2.0 & 3.0 & 2.0 & 40 & 1.0 & 5.0 & 5,0 \\
\hline Pertormance of Similar Project & & & & & & & 8.0 & 7.0 & 9.0 & 6.0 & 8.0 & 5.0 & 4.0 \\
\hline HSE and frate of Incident & & & & & & & & 2.0 & 40 & 3.0 & 2.0 & 40 & 5.0 \\
\hline Claims and Legal hssues & & & & & & & & & 4.0 & 2.0 & 3.0 & 3.0 & 4.0 \\
\hline Program of contractor Plissk Mansgement & & & & & & & & & & 5.0 & 2.0 & 6.0 & $\mathbf{8 . 0}$ \\
\hline Machinery and Equipment & & & & & & & & & & & 4.0 & 2.0 & 4.0 \\
\hline Accuracy in Technical Propesal & & & & & & & & & & & & 5.0 & 7.0 \\
\hline Khouledge of the Site. Resources and labors & & & & & & & & & & & & & $\mathbf{3 . 0}$ \\
\hline Time Pertormance in Past Experience & Incon: 0.06 & & & & & & & & & & & & \\
\hline
\end{tabular}

Fig. 6: The result of entry of data from Questionnaire Number 2 into the software.

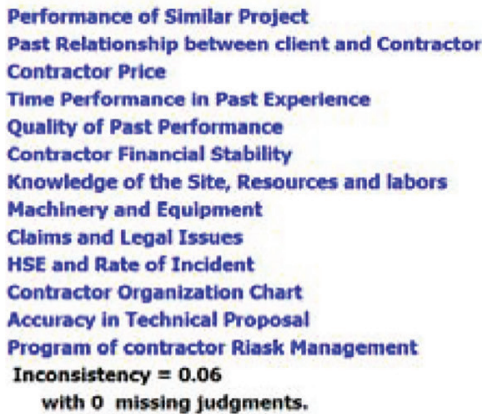

Fig. 7: The importance of factors.

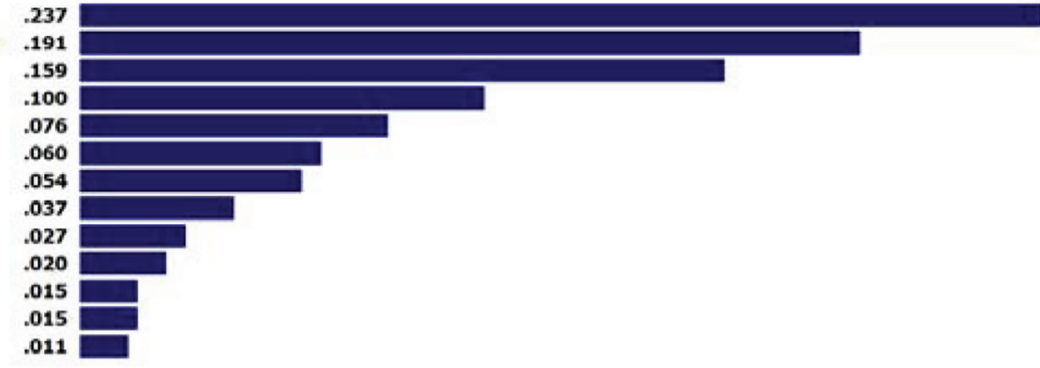

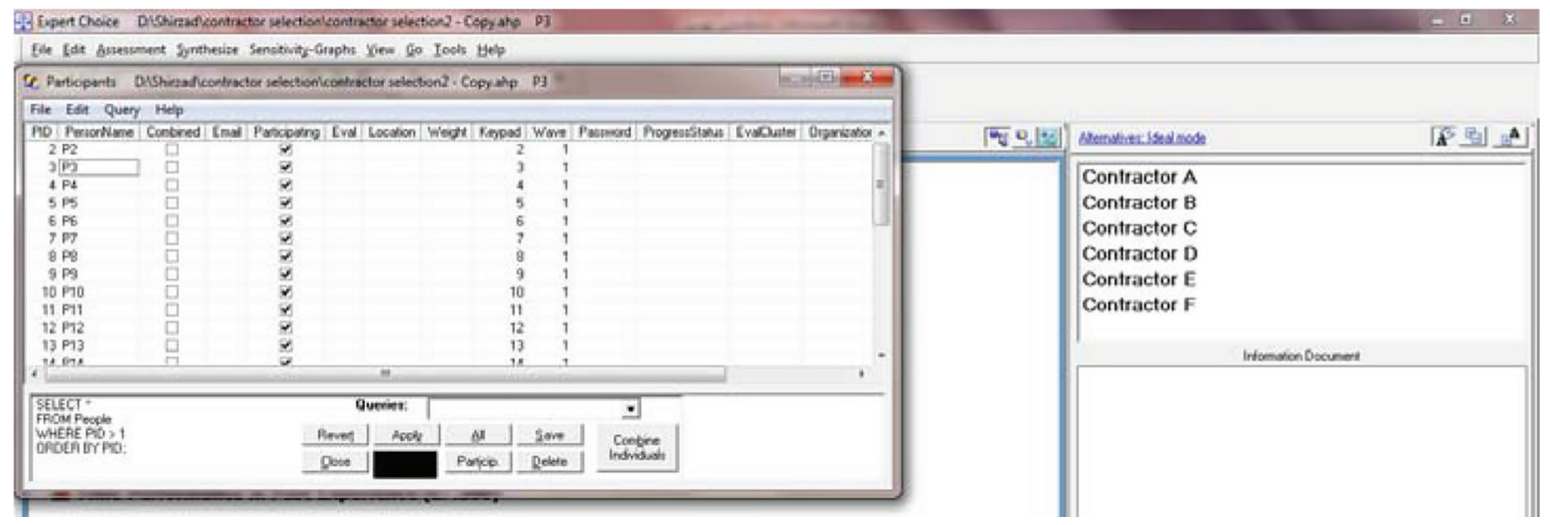

Fig. 8: The average of all the questionnaires. 
Tab. 2: Summary of the weights assigned to each factor.

\begin{tabular}{|c|c|c|}
\hline & Criteria & Weight \\
\hline 1 & Past relationship with contractor & 0.110 \\
\hline 2 & $\begin{array}{l}\text { Financial statements and contractor's financial } \\
\text { stability }\end{array}$ & 0.097 \\
\hline 3 & Contractor’s bid price & 0.096 \\
\hline 4 & Quality of past performance of the contractor & 0.093 \\
\hline 5 & $\begin{array}{l}\text { Appropriateness of contractor's organization } \\
\text { chart }\end{array}$ & 0.082 \\
\hline 6 & $\begin{array}{l}\text { The work experience in terms of performance of } \\
\text { similar projects }\end{array}$ & 0.077 \\
\hline 7 & HSE and rate of incidents in previous projects & 0.077 \\
\hline 8 & $\begin{array}{l}\text { Claims and legal issues of the previous projects } \\
\text { of the contractor }\end{array}$ & 0.076 \\
\hline 9 & $\begin{array}{l}\text { Documented program of risk management in } \\
\text { contractor's company }\end{array}$ & 0.068 \\
\hline 10 & $\begin{array}{l}\text { Having machinery and equipment appropriate } \\
\text { to the project }\end{array}$ & 0.062 \\
\hline 11 & $\begin{array}{l}\text { Accuracy of the documents in the technical } \\
\text { proposal }\end{array}$ & 0.061 \\
\hline 12 & $\begin{array}{l}\text { Sufficient knowledge of the site, resources, and } \\
\text { labor }\end{array}$ & 0.053 \\
\hline 13 & $\begin{array}{l}\text { Contractor's past record in terms of observing } \\
\text { timing }\end{array}$ & 0.046 \\
\hline
\end{tabular}

Now, this research shows the connection between these criteria and the main aim of the paper, which is risk management. With regard to the importance of the subject, these items are discussed in the following paragraphs.

\section{Past relationship with the clients}

The existence of past relation between contractor and client has a pivotal role in selecting the contractor by the owner again. Naturally, a congenial relation, firstly, creates a trusting atmosphere between them and, secondly, helps in terms of being familiar with the work culture of each other. Because of these reasons, previous positive interactions result in ending a new project with lower challenges. Thus, this criterion is identified as an important parameter during the process of contractors' selection.

2. Financial statement and contractor's affordability In many countries, a project is tendered when a client or a contractor provides all or a vast majority of the necessary budget for terminating that project. So, on the one hand, the contractor has no concern in terms of nonpayment of monthly invoices and lack of financial resources. On the other hand, the client does not worry about a delay in the project stemming from the deficiency of budget amount for the contractor. Nevertheless, in other countries, when a huge number of projects are tendered without providing the needed costs, the criterion of contractor's affordability is highlighted since not paying contractor's demand in time is considered a justified reason for a delay in the project by the contractors who do not possess strong financial background. Therefore, naturally, the contractors who do not meet this requirement definitely face many problems within a short period and also in the primary phases. Many projects that have been stopped by workers' strike are vivid examples of this issue. Thus, it is recommended to the owners to employ contractors with more financial power.

\section{Suggested price from the contractor}

As clients have specific budgets, the project price is viewed as one of the key factors determining the selection of the contractor. Therefore, the proposed price has to fit in with the owner's financial limitations. With regard to the position allocated to this criterion by the managers and experts, it is known to everyone that although choosing a contractor on the basis of project price is not a viable approach and project price is not the primary parameter, it is a crucial subject that must not to be ignored. As a result, it is true that the factor "suggested price" examines, besides other criteria, suitable qualifications, positive background, and proper scheduling. During the process of selection, the operating team experts optimally determine the domain price and pay attention to the possible risks arising from very high to very low price.

4. Following up the confirmed schedule plan in previous projects

Obligation to the confirmed schedule is one of the most significant factors that contractors must commit to completely. Because any delay vastly affects the financial value, profitability, and life cycle of a project, its importance is highly evident. Thus, conferring a new project to contractors with flawed background in terms of delays in delivering final products increases the possibility of transition of lag risk to the new project.

5. Successful experience in accomplishing the same projects historically

Doing a new project for the first time brings some unexpected challenges that the contractor may not have faced previously. Such problems happen even for the professional, experienced, and affordable contractors who have updated technologies. This means doing the same project for the second time will be logically accomplished in a shorter period of time, with greater quality, and in a simpler manner 
than the first one. Since clients will consequently pay the extra costs pertaining to the bad selection of inexperienced contractors, the risk of assigning projects to contractors who do not have successful experience with the same type of project in their records is not negligible.

\section{The project under study}

The case under study was determination of a subcontractor by a main contractor through a tender for a project that included the construction of a power station, transmission lines, and facilities related to them in order to supply electricity to a refinery. The project is located in Khuzestan Province in Iran, with an estimated cost of about US\$24.2 million, for accomplishment in 2 years, and in engineering, procurement, and construction (EPC) form.

A summary of contractors' information is provided in Table 3.

\section{Selection of the superior alternative and the final decision}

This paper analyzes the process of choosing an eligible contractor based on a two-stage method that includes pre-evaluation and the final selection of contractors. The aim of the first stage is preparing a short list of meritorious contractors to attend the tender process. The following items are asked from the contractors:

1. Contractor's ranking (confirmed by the Ministry of Roads and Urban Development)

2. Members of the management team and shareholders

3. Financial stability

4. Performance of similar projects

5. The qualification of past projects

6. The background of firm's establishment

7. Key experts

The contractors were assessed using these criteria, and those who could get the least score were allowed to attend the main tender (second phase). Six contractors qualified in the first stage, and in the next phase, they were ranked through the previously specified 13 factors that were extracted from the distributed questionnaires and weighted. Contractors' prioritizing was done by the Expert Choice software. Figure 9 shows the 13 items with respect to their weights.

The data from these criteria related to each contractor were entered into the software. The length of the blue strip illustrates the importance or priority of the contractor in terms of that specific factor. For example, contractor A is ranked first among the six contractors. The contractors are prioritized according to these items, as shown in Figures 10-22.

Tab. 3: A summary of contractors' information.

\begin{tabular}{|c|c|c|c|c|c|c|c|}
\hline & \multirow[t]{2}{*}{ Criteria } & \multicolumn{6}{|c|}{$\begin{array}{l}\text { Status of each contractor (points ranging from } 1 \text { to } 6 \text {, } \\
\text { the best to the worst) }\end{array}$} \\
\hline & & A & B & $\mathrm{C}$ & D & $\mathbf{E}$ & $\mathbf{F}$ \\
\hline 1 & Past relationship with contractor & 1 & 2 & 4 & 3 & 4 & 5 \\
\hline 2 & Financial statements and contractor's financial stability & 4 & 1 & 5 & 4 & 3 & 2 \\
\hline 3 & Contractor’s bid price & 5 & 2 & 1 & 5 & 3 & 6 \\
\hline 4 & Quality of past performance of the contractor & 3 & 4 & 1 & 6 & 2 & 5 \\
\hline 5 & Appropriateness of contractor's organization chart & 1 & 4 & 3 & 2 & 3 & 3 \\
\hline 6 & $\begin{array}{l}\text { The work experience in terms of performance of } \\
\text { similar projects }\end{array}$ & 5 & 4 & 1 & 1 & 2 & 3 \\
\hline 7 & HSE and rate of incidents in previous projects & 5 & 1 & 1 & 5 & 3 & 2 \\
\hline 8 & $\begin{array}{l}\text { Claims and legal issues of the previous projects of } \\
\text { the contractor }\end{array}$ & 6 & 5 & 3 & 4 & 2 & 1 \\
\hline 9 & $\begin{array}{l}\text { Documented program of risk management in } \\
\text { contractor’s company }\end{array}$ & 4 & 4 & 1 & 5 & 2 & 3 \\
\hline 10 & $\begin{array}{l}\text { Having machinery and equipment appropriate } \\
\text { to the project }\end{array}$ & 1 & 2 & 3 & 6 & 5 & 4 \\
\hline 11 & Accuracy of the documents in the technical proposal & 5 & 1 & 2 & 3 & 4 & 6 \\
\hline 12 & $\begin{array}{l}\text { Sufficient knowledge of the site, resources, } \\
\text { and labor }\end{array}$ & 3 & 1 & 4 & 5 & 2 & 6 \\
\hline 13 & Contractor's past record in terms of observing timing & 2 & 3 & 3 & 5 & 1 & 4 \\
\hline
\end{tabular}



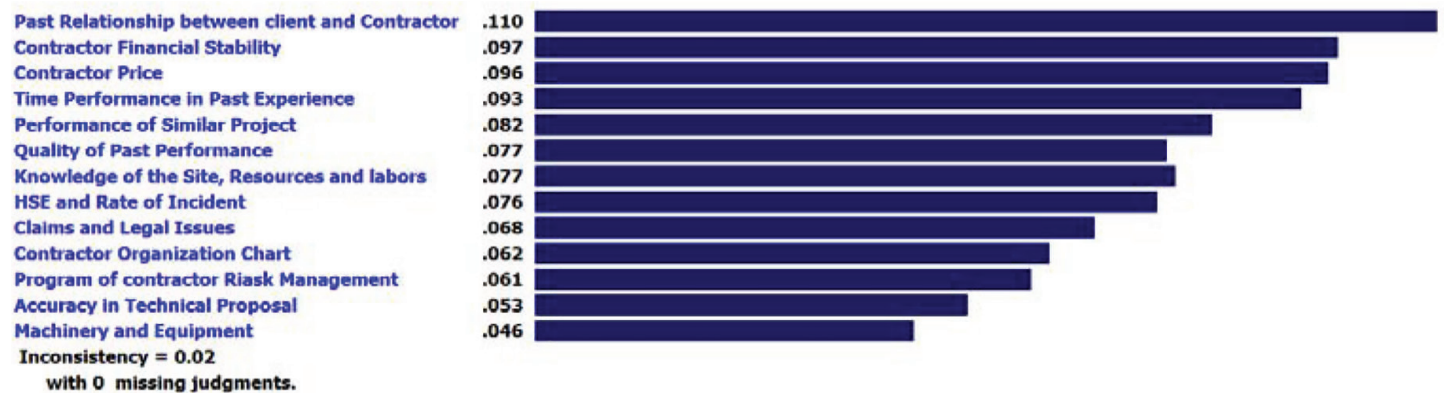

Fig. 9: Prioritizing using the 13 items and subsequent ranking by the software with regard to their weights.

\section{Past relationship between client and contractor:}

\section{Contracter A}

Contractor B

Contractor C

Contractor D

Contractor E

Contractor $F$

Fig. 10: The most eligible contractor: A.

\section{Financial stability:}

\begin{tabular}{|l|}
\hline Contracter A \\
Contracter B \\
Contracter C \\
Couttractet D \\
Cositractor E \\
\hline Centracter F \\
\hline
\end{tabular}

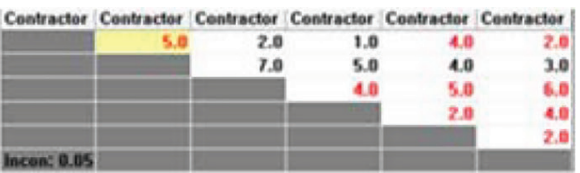

Fig. 11: The most eligible contractor: B.

\section{Contractor price:}

\section{Contracter A}

Contracter $\mathrm{B}$

Contractat C

Centractat D

Cositracter E
Costractor F

Fig. 12: The most eligible contractor: C.

\section{Quality of past performance:}

\begin{tabular}{|l|}
\hline Contracter A \\
Contractor B \\
Centracter C \\
Contractor D \\
Costractor E \\
Costractor F \\
\hline
\end{tabular}

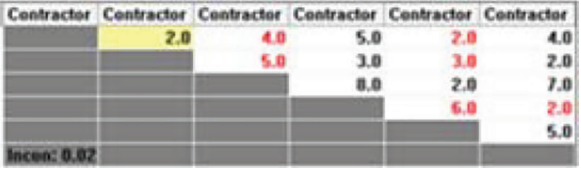

Fig. 13: The most eligible contractor: $\mathrm{C}$.

\section{Contractor organization chart:}
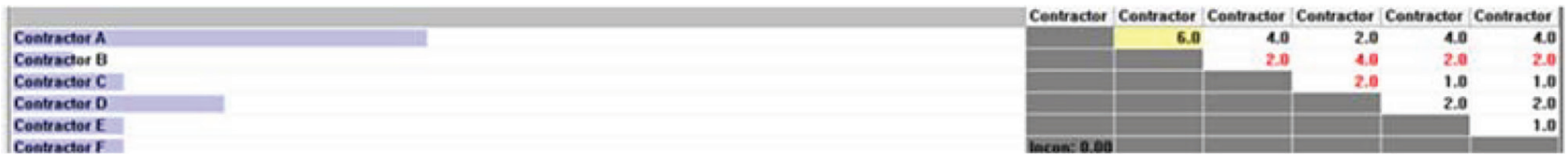

Fig. 14: The most eligible contractor: A. 
Performance of similar projects:
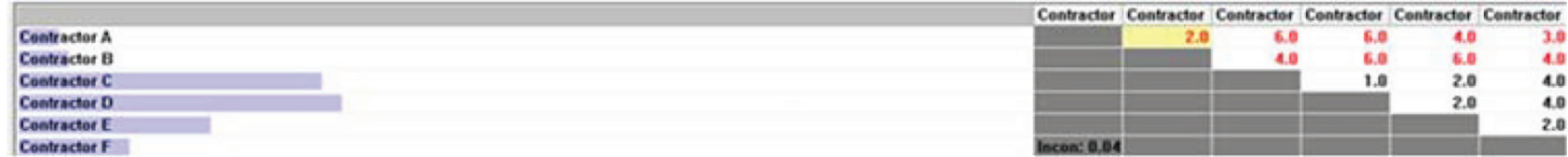

Fig. 15: The most eligible contractor: D.

\section{HSE and rate of incidents:}

\begin{tabular}{|c|c|c|c|c|c|c|}
\hline & Contractor & Contracter & Contractor & Contractoe & Contractor & Contracter \\
\hline Centracter A & & 6.0 & 2.0 & 2.0 & 2.0 & 4.0 \\
\hline Contracter B & & & 4.0 & 7.0 & 4.0 & 2.0 \\
\hline Contracter C & & & & 4.0 & 1.0 & 2.0 \\
\hline Centracter 0 & & & & & 4.0 & 6.0 \\
\hline Centractor E & & & & & & 20 \\
\hline Centracter F & lncee: 0.01 & & & & & \\
\hline
\end{tabular}

Fig. 16: The most eligible contractor: B.

\section{Claims and legal issues:}
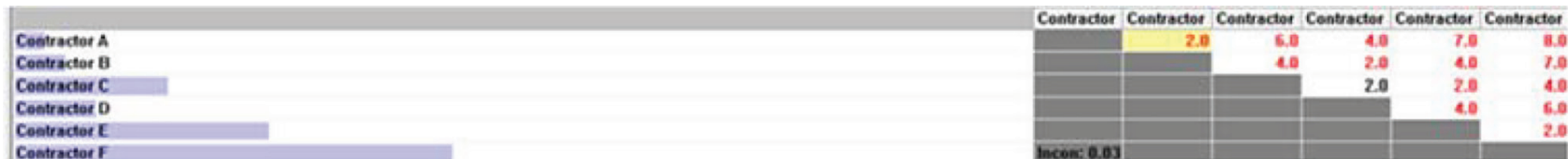

Fig. 17: The most eligible contractor: F.

\section{Program of contractor risk management:}

\begin{tabular}{l} 
Costracter $\mathrm{A}$ \\
Costracter $\mathrm{B}$ \\
Costracter C \\
Cestracter $\mathrm{D}$ \\
Contracter $\mathrm{E}$ \\
Contractor $\mathrm{F}$ \\
\hline
\end{tabular}

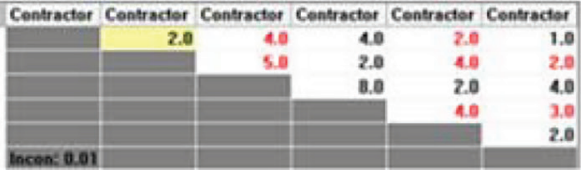

Fig. 18: The most eligible contractor: $\mathrm{C}$.

\section{Machinery and equipment:}

\section{Costracter A} Coatractot B

Cantractat $\mathrm{C}$

Coestracter D

Costracler $\mathrm{E}$

Costracter $\mathrm{E}$

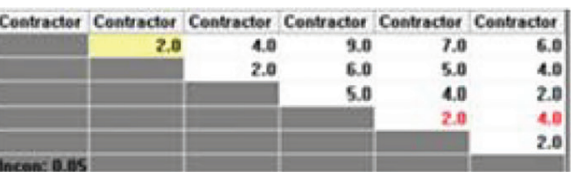

Fig. 19: The most eligible contractor: A.

\section{Accuracy in technical proposal:}
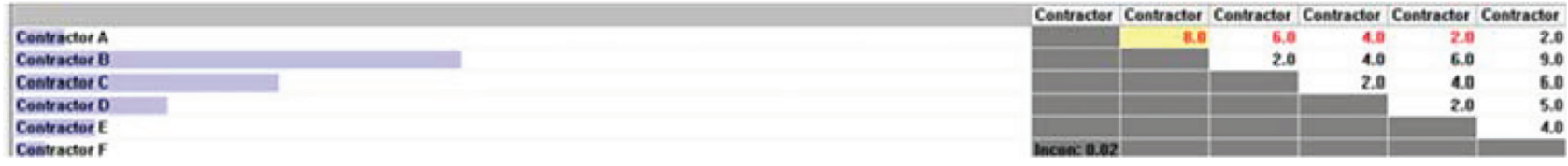

Fig. 20: The most eligible contractor: B. 


\section{Resources and labor:}

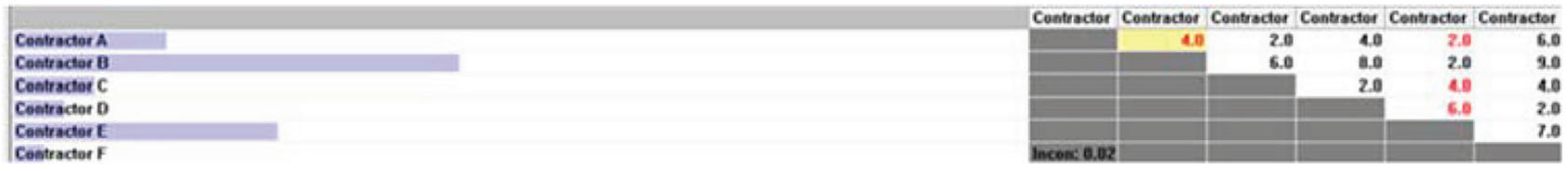

Fig. 21: The most eligible contractor: B.

\section{Time performance in the past:}

\begin{tabular}{l} 
Contracter A \\
Costrador B \\
Contracter C \\
Contractor D \\
Contracter E \\
Costractor F \\
\hline
\end{tabular}

Fig. 22: The most eligible contractor: $\mathrm{E}$.

After completing the process of recording information pertaining to all contractors, the most qualified contractor is introduced by synthesizing data. As Figure 23 shows, contractor B achieved a numerical value of 0.219 , and it could win the tender process. Contractors $\mathrm{C}$ and $\mathrm{D}$ are ranked as second and last alternatives, respectively.

\section{Results}

As mentioned in the previous section, contractor " $\mathrm{B}$ " was the winner of the tender. But if the contractor was selected just based on the lowest price and regardless of other factors, contractor "C" would have been selected as the winner. Now, the reason for selecting contractor "B" and not selecting contractor "C" is discussed in this section. Table 4 shows the comparison of the importance of contractors "B" and "C".

According to this table, contractor "B" was the first in four of the evaluation criteria and contractor " $\mathrm{C}$ " was in the first place in five criteria. A look at the weight of the criteria suggests that the maximum weight is for "financial statements of the contractor", and the criterion of "contractor bid price" was in the second place. Contractor " $\mathrm{B}$ " was in the first and second places in terms of these two criteria, but contractor "C" was in the fourth and first places, respectively. The two contractors are in the same status considering the criteria of knowledge of resources and the quality of previous projects, with relatively high weights (0.077). The contractor " $\mathrm{B}$ " was in the first and fourth places, and contractor " $\mathrm{C}$ " was in the fourth and first places, respectively, for these criteria. There are some modest differences between the two contractors, and contractor "C" even has a comparative advantage. Due to the low weight of the items, the superiority was virtually unnoticeable, and the final superiority is for contractor "B" (Figure 23).

\section{Conclusion}

Providing significant qualitative data to help clients creates a proper evaluation program, resulting in the success of the project. In the planning phase of a construction project, the owner must decide what level and method must be used to evaluate the contractor. A congenial evaluation results in the lowest percentage of increase in project timing. Contractor evaluation alone is a definite indicator of the success of projects.

Since the bulk of financial resources of development projects is spent on the costs of operations, the implementation of each project needs a contractor with capabilities appropriate to the project to prevent an undue increase in administrative costs and to accomplish the project within the assigned time and with the anticipated resources. Therefore, wrong decisions and lack of attention to proper scientific methods and techniques of deciding on the selection of contractors impose large losses on the organization and society. Consequently, development projects often run into problems such as lengthening of the time or reduction in quality caused by lack of a proper choice for the project.

\section{Challenges in contractor selection}

Contractor selection solely on the basis of the lowest price faces the risk of not choosing the right contractor who possesses the necessary abilities. The criterion of the lowest 


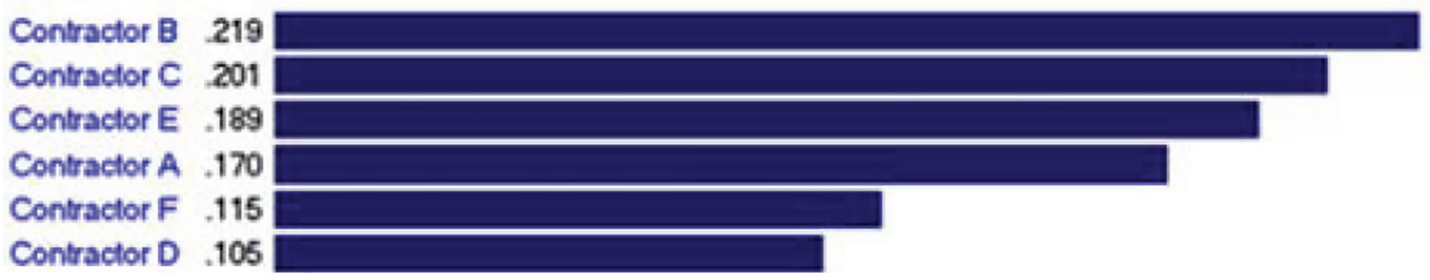

Fig. 23: Contractor selection, phase 2 (overall rating of contractors).

Tab. 4: Comparison of the importance of contractors "B" and "C"

\begin{tabular}{|c|c|c|c|}
\hline Criteria & Weight & $\begin{array}{l}\text { Rank of } \\
\text { Contractor } \\
\text { "B" }\end{array}$ & $\begin{array}{l}\text { Rank of } \\
\text { Contractor } \\
\text { "C" }\end{array}$ \\
\hline $\begin{array}{l}\text { Financial statements and } \\
\text { contractor's financial } \\
\text { stability }\end{array}$ & 0.097 & 1 & 4 \\
\hline $\begin{array}{l}\text { HSE and rate of incidents } \\
\text { in previous projects }\end{array}$ & 0.076 & 1 & 1 \\
\hline $\begin{array}{l}\text { Accuracy of the documents } \\
\text { in technical proposal }\end{array}$ & 0.053 & 1 & 2 \\
\hline $\begin{array}{l}\text { Sufficient knowledge of the } \\
\text { site, resources, and labor }\end{array}$ & 0.077 & 1 & 4 \\
\hline Contractor's bid price & 0.096 & 2 & 1 \\
\hline $\begin{array}{l}\text { Quality of past performance } \\
\text { of the contractor }\end{array}$ & 0.077 & 4 & 1 \\
\hline $\begin{array}{l}\text { The work experience in } \\
\text { terms of performance of } \\
\text { similar projects }\end{array}$ & 0.082 & 4 & 1 \\
\hline $\begin{array}{l}\text { Documented program of } \\
\text { risk management in con- } \\
\text { tractor's company }\end{array}$ & 0.061 & 4 & 1 \\
\hline
\end{tabular}

bid makes some contractors resort to every trick in order to win tenders. For example, they offer great and unreasonable discounts in client's estimation and they win the tender as a result of the weakness of existing laws and regulations for contractor selection, and thus, multiple problems occur in the process of implementing the project. On the other hand, a number of contractors believe that the method of selecting the contractor in many cases does not lead to the actual selection of the best contractor. This reduces the incentives to motivated, qualified, and competent contractors for tendering.

\section{The proposed method}

The proposed method not only is based on the lowest bid but also considers several factors that are more crucial in the tendering phase and, from the client's view, in contractor selection. Comparisons of ratings and ranking factors with each other and determination of their importance was one of the goals of this study, which were achieved by designing a questionnaire and asking experts' opinion. The AHP was adopted to perform this work and achieve pairwise comparison of options. In addition to being simple and easy, this method makes it possible to use qualitative and quantitative criteria simultaneously, and it is also capable of controlling the logical compliance of the judgments used in rating. The method is also capable of providing the final ranking of options.

\section{Limitations and weaknesses of the study}

One of the problems in this study was the long process of questionnaire completion and return, especially the AHP-based questionnaire. Logical relationship between the answers is one of the requirements of the AHP, i.e., if parameter $\mathrm{X}$ is more important than parameter $\mathrm{Y}$ and parameter $\mathrm{Y}$ is also more important than parameter $\mathrm{Z}$, parameter $\mathrm{X}$ will definitely be more important than $\mathrm{Z}$. If the answers are not in this way, the result is not reliable. In this study, there was no logical relationship between the responses. Therefore, six questionnaires out of 36 questionnaires were eliminated from the process.

Two points can be mentioned as the weaknesses of AHP: the hierarchical structure is a one-sided relationship because the criteria are merely selected to choose the options, but if the options affect the criteria, the method cannot be used anymore. The second weakness of this model is its dependence on software because difficult and long calculations are done more easily using the software.

\section{Suggestions for further study}

This study was not done on a single working society such as contractors, consultants, or clients separately. Carrying out further studies on single working groups, such as contractors or clients, separately can help understand the differences in views regarding contractor selection. Furthermore, factors and their weights can suggest the working culture of a client or a consultant, and the results for a 
company may be the same. By conducting such studies and obtaining the results for different companies, the different views and cultures of companies toward contractor selection and risk management can be understood.

\section{Discussion about sensitivity}

To determine an eligible contractor, consultant, or investor for different contracts, there is the possibility of change in the weights of the 13 factors, or even removal of criteria or addition of new ones. Then, the inputs for the software (Expert Choice) will be changed, and consequently, the final result may change. For example, in high-technology projects that are done for the first time, the factor "performance of similar projects" does not work practically, and criteria such as accessibility and ability to apply high-technology equipment by considering their weights as one of the 13 factors can affect the selection of final contractors. However, in international projects, when the clients need to select international companies, they typically face problems in finding information about "past relationship of companies with their clients" or find ambiguities in the construction laws in the origin country, so the weight of this item may differ relative to that in common contracts.

\section{References}

Alhazmi, T., \& McCaffer, R. (2000). Project procurement system selection model. Journal of Construction Engineering and Management, 126(3), pp. 176-184.

Anagnostopoulos, K., \& Vavatsikos, A. (2006). "An AHP model for construction contractor prequalification, operational research". An International Journal, 6, pp. 333-346.

Asgharizadeh, E., \& Nasrollahi, M. (2009). Identification and selection of weight of factors affecting contractor selection in construction projects. Journal of Management Research, winter 2009(2), pp. 105-122.

Fong, P. S., \& Choi, S. (2000). Final contractor selection using the analytical hierarchy process. Construction Management and Economics, 18, pp. 547-577.
Haghighi Fard, A. (2010), Selection of machinery in surface mines using analytic hierarchy process. Master thesis, Amirkabir University of Technology, Tehran, Iran

Holt, G. D. (2010). Classifying construction contractors. Building Research and Information, 25(6), pp. 374-382.

Huang, X. (2011). An analysis of the selection of project contractor in the construction management process. International Journal of Business and Management, 6(3), pp. 184-189.

Iyer, K. C., \& Jha, K. N. (2005). Factors affecting cost performance: evidence from Indian construction projects. International Journal of Project Management, 23(4), pp. 283-295.

Jaselskis, E. J., \& Russell, J. S. (1992). Risk analysis approach to selection of contractor evaluation method. Construction Engineering Management, 118(4), pp. 814-821.

Laryea, S., \& Hughes, W. (2011). Risk and price in the bidding process of contractors. Journal of Construction Management and Engineering, 137(4), pp. 248-258.

Ledezema, E. L., \& Fernandez, N. Q. (2012). Risk management in the bidding process. Master thesis, KTH Royal Institute of Technology in Stockholm.

Mohagher, A., Kashi, K., \& Salami, H. (2012). Selection of contractor for construction projects using a combination of multi-attribute utility theory and Electre method in the base Company. Journal of Industrial Management, summer 2012(8).

Nieto-Morote, A., \& Ruz-Vila, F. (2012). A fuzzy multi-criteria decision-making model for construction contractor prequalification. Automation in Construction., 25, pp. 8-19.

Plenkiewicz, E. (2009). Contractor prequalification model using fuzzy sets. Journal of Civil Engineering and Management, 15(4), pp. 377-385.

Rajae, H., \& Hazrati, A. (2007). Fuzzy Saw and Fuzzy Topsis multi-criteria decision-making models for pre-qualification and selection of contractors and comparing the results. In: Project Management proceeding of the 4 th International Conference in Tehran, Iran, 2007, pp. 115-132.

Sari, A., \& El-Sayegh, S.M. (2007). Factors Affecting the Selection of the Appropriate Construction Management at Risk Contractor. In: Latin American and Caribbean proceeding of the international Conference for Engineering and Technology in Tampico, México, 2007, pp. 5C.1-2 - 5C.1-8.

Sik, P. A., Fong, W., \& Choi, K. Y. (2000). Final contractor selection using the analytical hierarchy process. Construction management and economics, 18(5), pp. 547-557.

Zavadskas, E. K., Turskis, Z., \& Antucheviciene, J. (2015). Selecting a contractor by using a novel method for multiple attribute analysis: weighted aggregated sum product assessment with grey values (WASPAS-G). Studies in Informatics and Control, 24(2), pp. 141-150. 